\title{
Who provides patients with drug information?
}

\author{
TERESA MCMAHON, CHRISTINE M CLARK, GEORGE R BAILIE
}

\begin{abstract}
One hundred and fifty four patients were interviewed to determine the type and source of information that they had received about drugs that had been prescribed for them. Most had been told how often to take the drugs $(145(94 \%))$ and how much to take each time (143 (93\%)), but few had been informed about side effects $(49(32 \%))$ and fewer had received written information $(22$ (14\%)). Pharmacists most commonly supplied information about how often to take the drugs $(105(68 \%))$, how much to take each time $(99(64 \%))$, and the best way to take it $(109(71 \%))$. Doctors most often gave information about duration of treatment (116 $(75 \%))$ and possible side effects $(126(82 \%))$. Few patients requested specific information on their own initiative.

More research is needed to determine how best to communicate drug information to patients.
\end{abstract}

\section{Introduction}

Patients' failure to adhere to drug regimens is a recognised source of failed treatment. ${ }^{1}$ Up to half of all patients do not take their drugs as prescribed and may stop treatment when they feel better. ${ }^{2}$ This may be a result of a deliberate action by the patient or a misinterpretation, or inadequate provision, of information. Compliance is increased by some knowledge of the disease and its treatment. ${ }^{3}$

\footnotetext{
Department of Pharmacy, University Hospital, Seattle, Washington, United States

TERESA MCMAHON, PHARMD, clinical pharmacist

Manchester University Department of Pharmacy, Hope Hospital, Salford M6 8HD

CHRISTINE M CLARK, MPS, principal pharmacist GEORGE R BAILIE, MSC, PHARMD, principal pharmacist

Correspondence to: Dr Bailie.
}

Verbal instructions reinforced by written information may increase knowledge and improve outcome. ${ }^{46}$ The extent to which such combined information is given is unknown. In many pharmacies the prescription is often sealed in a bag and passed to the patient by an assistant with no verbal instructions. Seemingly, the pharmacist assumes that the patient has already received adequate instructions and has understood.

We studied the extent to which patients are given verbal and written information, the primary source of the information, and the types of information sought by patients on their own initiative.

\section{Patients and methods}

An independent assessor interviewed outpatients in a teaching hospital immediately after their prescriptions had been dispensed. The pharmacists were unaware of the interviews. A standard questionnaire was used, and interviews proceeded if patients were prescribed one of the following 15 drugs: analgesics; non-steroidal anti-inflammatory drugs; glyceryl trinitrate; cimetidine or ranitidine; antibiotics; anticoagulants; oral steroids; oral contraceptives; tricyclic antidepressants; iron salts; benzodiazepines; liquid preparations for children; eye preparations; vaginal preparations; or inhalers.

These target drugs were chosen as they comprised a large proportion (45$50 \%$ ) of the prescriptions, required definite information on use and side effects, and had important interactions or entailed complex regimens or techniques for use. Patients were excluded if their drugs were prescribed and dispensed on different days; if they were medical or nursing staff, if they could not communicate, or if they refused to participate. If more than one target drug was prescribed only one was selected; new drugs were selected in preference.

\section{Results}

We approached 349 outpatients for interview, of whom 154 (44\%) were taking a target drug (table 1). Of the remaining 195 patients, $22(11 \%)$ refused to participate and $173(89 \%)$ were taking non-target drugs. Of the 154 patients, $70(45 \%)$ had previously used the target drug. Table II shows the proportion of information given by pharmacists, doctors, and nurses. Most patients were told how often to take the medicine and how much to 
TABLE I-No(\%) of patients taking target drugs

\begin{tabular}{|c|c|c|c|}
\hline $\begin{array}{l}\text { Antibiotics } \\
\text { Non-steroidal anti-inflammatory } \\
\text { drugs } \\
\text { Oral steroids } \\
\text { Analgesics } \\
\text { Eye preparations } \\
\text { Inhalers } \\
\text { Anticoagulants }\end{array}$ & $\begin{array}{l}27(18) \\
26(17) \\
23(15) \\
19(12) \\
14(9) \\
13(8) \\
7(5)\end{array}$ & $\begin{array}{l}\text { Iron supplements } \\
\text { Vaginal preparations } \\
\text { Tricyclics } \\
\text { Benzodiazepines } \\
\text { Liquid preparations for children } \\
\text { Cimetidine/ranitidine } \\
\text { Oral contraceptives } \\
\text { Glyceryl trinitrate }\end{array}$ & $\begin{array}{l}6(4) \\
6(4) \\
5(3)\end{array}$ \\
\hline
\end{tabular}

TABLE II-No(\%) of 154 patients who received information

\begin{tabular}{lccccc}
\hline & \multicolumn{5}{c}{ Source of information } \\
\cline { 2 - 5 } & & & & \multicolumn{3}{c}{ Doctor and } \\
Topic discussed with patient & Doctor & Nurse & Pharmacist & pharmacist & Total \\
\hline How often to take drugs & $91(63)$ & $4(3)$ & $98(68)$ & $47(30)$ & $145(94)$ \\
How much to take each time & $89(62)$ & $2(1)$ & $92(64)$ & $41(29)$ & $143(93)$ \\
Best way to take drugs & $27(34)$ & $3(4)$ & $56(71)$ & $10(13)$ & $79(51)$ \\
Duration of treatment & $61(75)$ & $2(2)$ & $25(33)$ & $8(10)$ & $81(53)$ \\
Side effects of treatment & $41(82)$ & & $10(20)$ & $4(8)$ & $50(32)$ \\
Concomitant drugs & $63(93)$ & $1(1)$ & $6(10)$ & $2(3)$ & $68(44)$ \\
Allergies & $44(94)$ & $1(2)$ & $1(2)$ & & $47(31)$ \\
\hline
\end{tabular}

take each time. About half were informed how best to take the medicine and for how long to take it. Fewer patients were informed about side effects or asked about allergies or concomitant drugs. Only $21(14 \%)$ patients stated that they had ever received written information, yet $114(74 \%)$ claimed that they would find such information valuable.

Table III shows how often patients themselves asked questions about their drugs. Pharmacists and doctors provided most information. Pharmacists most commonly gave information about how often to take the drugs, how much to take each time, and the best way to take it. Pharmacists were also the main providers of written instructions. Doctors most often gave information about the duration of treatment and possible side effects and asked about allergies and concurrent medicines.

TABLE III-Drug information requested by outpatients

\begin{tabular}{ll}
\hline Information requested & No (\%) \\
\hline Side effects of treatment & $43(28)$ \\
How often to take drug; & $53(34)$ \\
Best way to take drugs & $31(20)$ \\
Duration of treatment & $50(32)$ \\
Action of drugs & $50(32)$ \\
\hline
\end{tabular}

\section{Discussion}

Over $90 \%$ of patients in this study received information about the treatment regimen, but substantially fewer were told how best to take the drug and the duration of treatment. There is definitely a best way to use inhalers, for example, but the case is less clear for antibiotics. Among those prescribed target drugs for which there is an undisputed best way (glyceryl trinitrate, eye and vaginal preparations, and inhalers) the proportion who were told the best way to take them was virtually the same as that among those prescribed other drugs (55\%), but more prescribers than pharmacists provided this information ( $44 \%$ and $39 \%$, respectively). Thus those providing information, especially pharmacists, do not select the drugs for which they provide information.

Only a third of patients were informed about side effects of the target drugs. Patients taking drugs with more serious side effects (steroids, anticoagulants, and non-steroidal anti-inflammatory drugs) received more information compared with those taking drugs with less serious side effects (63\% and $32 \%$, respectively). Doctors provided most of this information (79\%).

Doctors and pharmacists do not always give instructions, and when they do patients may not understand them. ${ }^{7}$ A recent study of over 8000 patients found that they knew little about various aspects of their treatment. ${ }^{8}$ In spite of this, however, patients rarely sought additional information. Similarly, less than a third of our patier had ever asked any questions about their drugs (table III). Only $14 \%$ of patients received written information despite the amount of such information available.' Careful, well planned verbal education patients by pharmacists has been shown to improve the ability of patients to recall information about their treatment. ${ }^{10}$ Writte information on drug treatment is generally considered to beneficial, ${ }^{71}$ and the combination of verbal and written informetion is probably the most effective. Interestingly, the number of patients in this study who desired written information (74\%) compares closely to that reported elsewhere $(83 \%) .^{12}$

The pharmacist is generally the last practitioner the patient sees in hospital and may therefore be an influential source information. The prescribers' instructions can be reinforced apd supplemented, and the patient can be encouraged to ask questions. In addition, the patient can be told about the drugs and see themat the same time. There is considerable room for improvement in the provision of drug information to patients, and more research might help to clarify patients' concerns with regard to drugs. Health cawe providers need to determine how best to communicate importaht information to patients so that they understand and remember it: Carefully designed leaflets containing drug information seem to particularly important.

\section{References}

1 Blackwell B. Drug therapy: patient compliance. N Engl f Med 1973;289:249-53. 2 Evans L, Spellman M. The problem of non-compliance with drug therapy. Drugs 1983;25:63-76 3 Eraker SA, Kirscht JP, Becker MH. Understanding and improving patient compliance. Ant

Intern Med 1984;100:258-68.
4 Colcher IS, Bass JW. Penicillin treatment of streptococcal pharyngitis: a comparison of schedutes and the role of specific counselling. JAMA 1972;222:657-9.
J

5 Morris LA, Halperin JA. Effects of written drug information on patient knowledge compliance; a literature review. Am $\mathcal{f}$ Public Health 1979;69:47-52.

6 Myers ED, Calvert EJ. Information, compliance and side effects: a study of patients an antidepressant medication. Br f Clin Pharmacol 1984;17:21-5.

7 Anonymous. Drug information for patients: keep it simple. [Editorial.] Br Med $\mathcal{F}$ 1980;280:1399 8 Busson M, Dunn APM. Patients' knowledge about prescribed medicines. Pharmaceutical foumal 1986;236:624-6.

9 Sloan PJM. Survey of patient information leaflets. $\mathrm{Br}$ Med $\mathcal{J}$ 1984;288:915-9.

10 Woroniecki CL, McKercher PL, Flagler DG, et al. Effect of pharmacist counselling on diwg information recall. Am $\mathcal{F}$ Hosp P harm 1982;39:1907-10.

11 Health and Public Policy Committee, American College of Physicians. Drug information of patients. Ann Intern Med 1986;104:121.

12 Ridout S, Waters WE, George CE. Knowledge of and attitudes to medicines in the Southamp community. Brf Clin Pharmacol 1986;21:701-12.

(Accepted 20 November 1986)

When using a pneumatic tourniquet in an infant for an operation what are the siffe pressures to use for legs and arms? What is the maximum safe duration of use? 3

Safety in using pneumatic tourniquets depends, firstly, on limiting the loeg pressure on tissues beneath the tourniquet and, secondly, on controlling total ischaemia time. In the thin arm of an infant generous soft wrappings needed between the limb and the tourniquet. The cuff should be as wideras possible and the wider the cuff the lower the inflation pressure required $f$ produce effective ischaemia. ${ }^{1}$ Cuff pressure in the arm need exceed systoic pressure by only $50-75 \mathrm{~mm} \mathrm{Hg}$; in the leg double the systolic pressure with be adequate. In infants and children some bleeding may occur owing to the circulation through the intramedullary vessels of the bone ${ }^{3}$; such bleedift should not be taken as a sign to raise the inflation pressure to a potentialby dangerous level. The pressure gauge of a pneumatic tourniquet shoufd be regularly tested against a mercury manometer so that erroneous, ineffectively low pressures, or dangerously high pressures may be avoided. The penalty in the former case is an obscured operative field and in the latter nerve palsy. The maximum safe duration for total ischaemia is reported is being between one and three hours, but two hours appears always to be safe्ठ If longer periods of ischaemia are required the circulation to the lin should be re-established for ten minutes each hour.-MALCOLM H GOUG consultant surgeon, Oxford.

1 Newman RJ, Muirhead A. A safe and effective low pressure tourniquet. $\mathcal{J}$ Bone foint S\&g 1986;68:625-8.

2 Klenerman L. Tourniquet time-how long? The Hand 1980;12:231-4.
3 Pulvertaft RG. In: Rob C, Smith R, eds. Operative surgery. Vol. The hand. 3rd ed. Londo Butterworths, 1977:4. 